\title{
Direct marketing for multichannel retailers: Issues, challenges and solutions
}

Received: 13th January, 2002



\section{Behram J. Hansotia}

is co-founder, president and chief executive officer of InfoWorks. His expertise lies in designing information-intensive marketing processes for customer acquisition, development and win-back. The approach is embodied in InfoWorks's Customer Value Enhancement ${ }^{\mathrm{TM}}$ process. Behram's post-doctoral experience spans academia, industry and management consulting, with the past several years devoted exclusively to strategic database marketing. Behram is an adjunct professor in the graduate Integrated Marketing Communications programme at Northwestern University and serves on the editorial boards of the Journal of Interactive Marketing and the Journal of Database Marketing.

\section{Bradley Rukstales}

is the president of The Customer Asset Consulting Group Inc. He was previously at InfoWorks, where his responsibilities included creating marketing strategies for information-intensive businesses and developing comprehensive frameworks for organisations to use in relationship marketing. He also designed implementation plans and pilot programmes, and assisted clients with their infrastructure and application development issues. Brad has led projects that utilise a wide range of analytical techniques for clients in the financial services, telecommunications and retail industries. He earned an MBA from the University of Michigan in corporate strategy, marketing and finance.

Abstract This paper discusses some key challenges retailers face as they try to build customer relationships and motivate customers to shop more frequently at their 'real' and on-line stores and through their catalogues. With many retailers offering multiple avenues and formats for shopping, the challenges and complexity of making marketing investment decisions increases significantly. Besides the challenge of operating call centres and websites 24 hours a day, seven days a week, the entire systems and decision-making infrastructure increases substantially in a multichannel environment. Specifically, this paper discusses:

- the types of information companies need to collect to facilitate one-to-one marketing investments

- the 'incremental' marketing performance metrics they should track

- how marketing programmes may be designed by identifying 'late' customers and the types of products recent website visitors are most interested in

- a new modelling approach to predicting incremental customer performance and how marketing investments may be optimised through decision rules.

Dr Behram Hansotia InfoWorks, 10 South Riverside Plaza, Suite 1920, Chicago, Illinois 60606, USA.

Tel: +1312589 0261; Fax: +1 312559 1061; e-mail: bhansotia@ infoworks-chicago.com

\section{INTRODUCTION}

With the recent advent of the World Wide Web and e-commerce, consumers have more avenues for shopping, selecting and buying products than ever before. From department stores to specialty retailers, to independent shop owners, everyone is using two to three channels in bringing merchandise to customers, as well as attracting new and existing customers to their real and virtual stores. Besides their brick and 
mortar presence, many retailers use direct communications including mailers, catalogues, websites and e-mail to drive sales and revenues.

Operating with multiple channels creates numerous challenges and the decision making also becomes more complex, since the channels often interact at the discretion of the customer. A couple of examples will help illustrate this point. A customer receives a Coach catalogue. She is attracted to a purse that is offered for the first time. She notes the elegant styling, but does not pick up the phone and order right away. Later that week, she is in the mall and stops by the Coach store. Sure enough, the store has the same purse available. She buys the purse and also adds a silk scarf and a belt. Should the entire purchase be attributed to the catalogue?

Another customer shopping for a new desktop computer for his college bound daughter, sees a Dell computer promotional advertisement, with a specific URL and visits the Dell website. He configures the system he wants to buy and gets a printout. Later he discusses the system with his daughter who convinces him of some changes. $\mathrm{He}$ returns to the Dell site, reconfigures the system and gets a printout. Rather than place the order directly at the site, he decides to call the Dell 1-800 number. He places the order with a sales representative, since he wants reassurance that the system will be delivered to his daughter's dorm, just before he drops her off.

In these two examples, the Coach catalogue and the Dell advertisement are the initial communication channels, but not the final sales channel. Any analysis that is undertaken, needs to address these interactions explicitly and specifically take into consideration the different channel costs. Channel usage also needs to be explicitly included in any segmentation for developing customer insights, as well as in calculating such metrics as marketing costs per sale.

Key challenges arise when direct marketing is used to drive traffic to real or virtual stores. These include:

- an integrated view of the customer

- use of the right marketing performance metrics

- design of marketing programmes

- analysis and modelling for targeting customers based on incremental behaviours

- use of economic decision rules for marketing investments.

\section{AVAILABILITY OF TRANSACTION DATA}

Large retailers obtain customer level transaction data of store purchases, returns, etc. primarily through their customers' use of their private label credit cards. Some large retailers have also used reverse appending services to track purchases on bank credit cards. Large cash (cheque) purchases are also manually entered into the POS system together with the customer's name and address. Since catalogue and web purchases include product delivery, these purchases are typically well tracked at the customer level.

Reverse appending services, however, have been recently discontinued due to privacy concerns. Though this has created a certain amount of anonymity for consumers, it has the potential of creating significant gaps in the retailer's understanding of his customer base. Loyalty programmes are one way retailers are attempting to address this problem. Here, customers who sign up for the programme could register their credit cards and in this way a complete profile of customer-retailer interactions can be maintained in the customer database. 


\section{INTEGRATED VIEW OF THE CUSTOMER}

Typically, direct marketing customer databases hold the following types of information:

- purchase transaction data (products, prices, dates, order size, returns, back orders, etc.)

- credit data (payments, credit limit, 30, 60, 90 days past due)

- demographics (often through overbuys).

More sophisticated companies, in addition, also track:

— cost of goods sold

- contacts initiated by the company and the cost of each contact

- for services, benefits used by customers

- customer complaints and inquiries on 1-800 numbers, etc.

In a multichannel environment, in addition to the above, the following also need to be captured:

- contacts initiated by the company by channel: mail, outbound calls, e-mail

- contacts initiated by the customer: inbound calls, e-mail, website visits

- purchases made by channel: catalogue, store, website.

More and more e-tailers are registering customers and placing customer

identifiers on cookies when individuals visit their website for the first time. This way they can identify repeat visitors to their website. A website's log files can now track, by customer ID, each URL request. These data can then be used to develop a session table, which should record at the minimum:

— the date and time of each visit
- time spent on key areas of the site

- the path traversed through the site, in terms of key site areas

- purchases, if any, and purchase details.

The customer session records can then be combined to create a summary customer record that can be used to drive customer level analyses.

\section{PERFORMANCE METRICS}

Unlike the typical mail order company where no sales occur without one-to-one communications, for a retailer, many customers visit the company's stores, even when they do not receive direct communications. The question then is, how should the effectiveness of direct communication investments be measured? The authors recommend using incremental metrics to measure the effectiveness of the direct communications:

- cost per incremental sale

— incremental sales per dollar of direct marketing investment

— incremental return on investment (ROI)

— incremental net present value (NPV) etc.

To compute incremental performance metrics, it is necessary to hold aside a control cell whose composition is identical to the treatment cell. The control group, however, does not receive the contact. For instance, if a promotional mailing is sent to customers most likely to buy men's fashions, then the members of the control cell should also be selected with the same criterion. Table 1 shows how these incremental metrics get computed.

When computing average revenue, it is most accurate to include revenue from all channels (store, catalogue, Web) 
Table 1: Incremental performance metrics for promotion mailer

\begin{tabular}{lccc}
\hline & Treatment group & Control cell & Incremental \\
\hline Number of customers & 500,000 & 50,000 & \\
Number of buyers & 100,000 & 5,000 & $10 \%$ \\
Purchase rate & $20 \%$ & $10 \%$ & - \\
Cost per direct mail piece & $\$ 0.50$ & $\$ 55$ & $\$ 5.00^{*}$ \\
Average revenue per buyer & $40 \%$ & - & $\$ 13.00^{\star *}$ \\
Average gross margin & - & - & $398 \%{ }^{* \star *}$ \\
Marketing cost per incremental buyer & - & & \\
Incremental sales per dollar of marketing cost & - & & \\
Incremental ROI & & &
\end{tabular}

regardless of the type or goal of the promotion. For instance, a direct mailing designed to drive store traffic may result in an online purchase based on the channel preferences of the buyer at that time. This purchase should be included, as there may be incremental purchases in that channel due to the mailing.

The authors prefer to compute the incremental ROI at the gross margin level, since all other costs of operations would continue to exist, whether the promotional mailer was sent or not. The incremental gross profits created should therefore be viewed as contribution to overhead and net profits.

\section{DESIGNING MARKETING PROGRAMMES}

Driving traffic to an e-commerce website is similar in many respects to driving customers to stores. The preferred channels for the latter tend to be newspaper inserts and solo mailings. More sophisticated retailers even try to customise their direct communications based on customers' past purchasing behaviours, captured through a customer behavioural segmentation scheme. The timing of such mailings is often triggered by key dates such as Mother's Day, Valentines Day, back-to-school, etc.

\section{Marketing programmes based on purchase timing}

What is seldom used in mailing decisions is the concept of inter-purchase cycle time. The very best customers generally purchase different products with some regularity. If this can be established for the best customers, a company can track whether a customer who was expected to return to a store, did in fact do so. If the customer is 'late', a customised communication is sent out urging a timely return. Of course, the performance of these communications needs to be evaluated on an incremental basis. Targeting models can also be deployed to identify customers most likely to respond to such communications, on an incremental basis, to further improve the performance of these mailings. Decision rules based on expected incremental profit at the customer level can then be invoked to identify the late customers that should be contacted. Again, this is marketing to expectations.

\section{E-mail promotions based on site visits}

Many e-commerce sites use registration and cookie technology to identify customers, who visit their sites. This technology can be leveraged to send 
customised e-mails, not only to customers who buy, but also to customers who visit but do not buy anything. The process may work as follows:

- a short record is created for each site visitor, which includes product purchase, if any, key areas visited and time spent in each area of the site. If the customer had abandoned the shopping cart, the products of interest are available directly

- business rules can next be developed for e-mailing specific letters, based on the visitor's record

- within 24 hours customised e-mails are sent out (a control group is held out for measuring incremental performance)

- performance is tracked and reported on an incremental basis.

The content and design of the e-mails can be optimised through testing, and the business rules should be based on analysis of test results. It is important that discounts are used sparingly, so that customers are not trained to buy only after receiving e-mails featuring discounts. This is best done by tracking customers longitudinally to ensure that the long-run profits of the treated group continue to outperform that of the control.

Even when customers buy products, there are opportunities for incremental sales based on the browsing behaviour of the purchasing session. Products examined but not purchased, or complimentary products, can be offered the next day. If the customer decides to buy, the new product could be included in the existing order, without an additional shipping charge.

\section{ANALYSIS AND MODELLING}

The key challenge in building targeting models for driving traffic to a real or virtual store is that the model should identify customers most likely to be positively influenced by the communication. Traditionally, marketers have focused on response optimisation. This process involves building statistical models to identify which customers are most likely to respond to a mailing. In practice, however, these models tend to target customers who will purchase without a promotion, with little true incremental value being created. The targeting variable should therefore be incremental response, or, even better, incremental expected net profits.

Incremental performance models are built by including in the modelling sample customers who are marketed to, as well as those that are not. Both tree-based and regression analysis-based approaches could be used for this analysis.

Tree, or recursive partitioning-based approaches, like CHAID and CART, recursively split the sample into groups, based on the values of predictor variables so that the difference in the mean value of the criterion variable for the resulting groups is maximised. The criterion variable could be response/non-response, or it could be a continuous variable such as revenues or order size of responding customers. Because the method employs recursive partitioning, each split results in sequentially smaller samples. An incremental response tree is similar to a response tree, except the sample includes both 'treated' and 'control' customers. The sample in this case is recursively split based on incremental response rates. Table 2 shows the calculations for incremental response rates for levels $\mathrm{A}$ and $\mathrm{B}$ for predictor variables $\mathrm{X}_{1}$ and $\mathrm{X}_{2}$ respectively.

Splitting the sample on predictor variable $X_{2}$, at $B$, results in a larger value in difference in incremental response rates $(1.2$ per cent $v s$. 0.5 per cent) than 
Table 2: Incremental response rates based on two different splitting variables

\begin{tabular}{|c|c|c|}
\hline & Split 1 & Split 2 \\
\hline Predictor Variable, $\mathrm{X}_{1}$ & $\leq \mathrm{A}$ & $>\mathrm{A}$ \\
\hline Treatment RR & $4 \%$ & $3 \%$ \\
\hline Control RR & $2.5 \%$ & $2 \%$ \\
\hline Incremental RR & $1.5 \%$ & $1 \%$ \\
\hline Difference in inc. RR & \multicolumn{2}{|c|}{$0.5 \%$} \\
\hline Predictor variable, $\mathrm{X}_{2}$ & $\begin{array}{l}\leq \mathrm{B} \\
35 \%\end{array}$ & $>\mathrm{B}$ \\
\hline Control RR & $1.8 \%$ & $2.7 \%$ \\
\hline Incremental RR & $1.7 \%$ & $0.5 \%$ \\
\hline Difference in inc. RR & \multicolumn{2}{|c|}{$1.2 \%$} \\
\hline
\end{tabular}

splitting the sample on predictor variable $\mathrm{X}_{1}$, at $\mathrm{A}$. Hence, in the incremental tree, the split on $\mathrm{X}_{2}$ would be selected over the split on $\mathrm{X}_{1}$.

Like CHAID, the incremental response tree evaluates splits at predefined levels of each predictor variable and picks the predictor variable and its level that maximises the difference in incremental response rates. This results in new subsamples, which are further split, as long as the differences are statistically significant, or the resulting sample sizes larger than the specified minimum size. Figure 1 shows an example of an incremental response tree. Since the tree technology is very sample dependent, when there are significant data, multiple trees are often built on separate samples and then develop a validation gains table using yet another sample. This gains table is built by identifying the end node that each observation in the validation sample falls in, in each tree, and calculating an average incremental response score. The validation sample is then sorted by score and divided into segments. The observed incremental response rates are then calculated for each segment. Table 3 is the resulting gains table developed from three trees, with Figure 1, being one of the trees.

Logistic regression models may also be used to estimate incremental response rates. Here, separate models are built for the treatment and control groups and

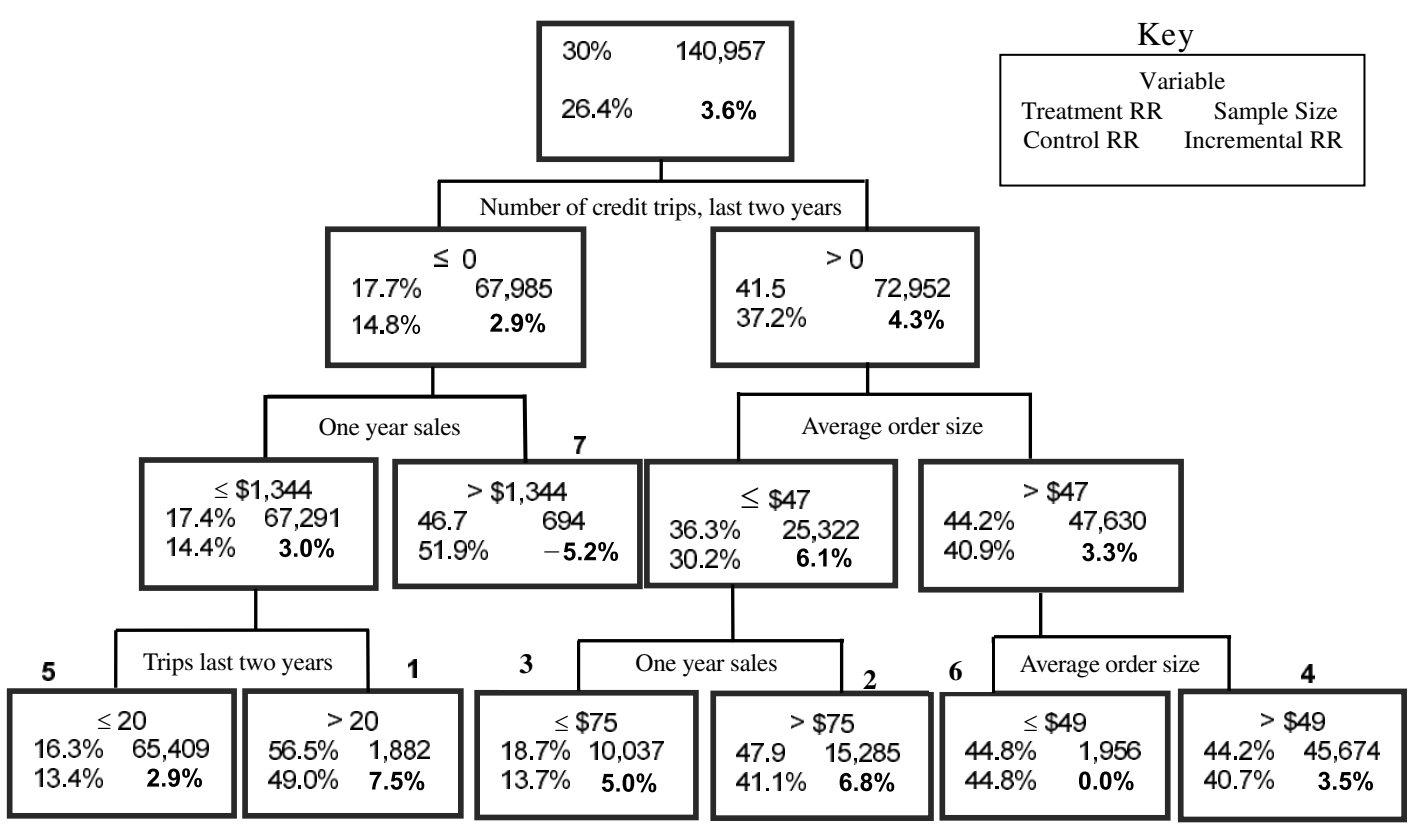

Figure 1: Incremental response tree 
Direct marketing for multichannel retailers: Issues, challenges and solutions

Table 3: TREE validation sample final incremental diagnostics

\begin{tabular}{lllllll}
\hline Segment & $\begin{array}{l}\text { Percentage } \\
\text { of file } \\
\%\end{array}$ & $\begin{array}{l}\text { Predicted } \\
\text { incremental } \\
\%\end{array}$ & $\begin{array}{l}\text { Treatment } \\
\%\end{array}$ & $\begin{array}{l}\text { Observed } \\
\text { control } \\
\%\end{array}$ & $\begin{array}{l}\text { Cumulative } \\
\text { Incremental } \\
\%\end{array}$ & $\begin{array}{l}\text { incremental } \\
\%\end{array}$ \\
\hline 1 & 9.9 & 7.7 & 48.7 & 41.1 & 7.5 & 7.5 \\
2 & 8.8 & 5.5 & 33.7 & 28.3 & 5.3 & 6.5 \\
3 & 11.4 & 4.3 & 30.5 & 26.1 & 4.4 & 5.7 \\
4 & 8.9 & 3.7 & 19.1 & 15.2 & 3.9 & 5.3 \\
5 & 12.4 & 3.4 & 49.6 & 46.1 & 3.5 & 4.8 \\
6 & 11.9 & 3.2 & 24.7 & 21.4 & 3.3 & 4.6 \\
7 & 26.2 & 2.7 & 9.2 & 7.3 & 1.9 & 3.8 \\
\hline
\end{tabular}

Table 4: Validation sample final incremental diagnostics

\begin{tabular}{rlllllll}
\hline \multicolumn{7}{l}{ Predicted response rates } & \multicolumn{2}{l}{ Observed response rates } \\
Decile & $\begin{array}{l}\text { Treatment } \\
\%\end{array}$ & $\begin{array}{l}\text { Control } \\
\%\end{array}$ & $\begin{array}{l}\text { Incremental } \\
\%\end{array}$ & $\begin{array}{l}\text { Treatment } \\
\%\end{array}$ & $\begin{array}{l}\text { Control } \\
\%\end{array}$ & $\begin{array}{l}\text { Incremental } \\
\%\end{array}$ & $\begin{array}{l}\text { Cumulative } \\
\text { incremental } \\
\%\end{array}$ \\
\hline 1 & 45.0 & 37.7 & 7.3 & 45.5 & 39.3 & 6.2 & 6.2 \\
2 & 38.3 & 32.7 & 5.6 & 38.9 & 32.8 & 6.1 & 6.1 \\
3 & 34.7 & 29.8 & 4.9 & 33.8 & 30.4 & 3.4 & 5.2 \\
4 & 31.8 & 27.5 & 4.3 & 31.3 & 27.8 & 3.6 & 4.8 \\
5 & 29.4 & 25.5 & 3.9 & 28.8 & 25.0 & 3.8 & 4.6 \\
6 & 26.3 & 22.9 & 3.4 & 26.4 & 22.9 & 3.5 & 4.4 \\
7 & 22.6 & 19.6 & 3.0 & 22.7 & 20.2 & 2.6 & 4.2 \\
8 & 19.5 & 17.0 & 2.5 & 19.1 & 16.8 & 2.4 & 3.9 \\
9 & 18.2 & 16.2 & 2.0 & 18.7 & 15.8 & 2.9 & 3.8 \\
10 & 34.1 & 33.5 & 0.6 & 34.6 & 32.3 & 2.3 & 3.7 \\
\hline
\end{tabular}

each customer is scored on both models. The difference in predicted scores is then used to sort the combined treatment and control samples and this combined sample is then divided into deciles. For each decile an average incremental response rate is now calculated. This allows an incremental response score to be mapped into observed response rates. Table 4 is an example of a gains table built on an incremental response score.

In a study on modelling incremental response rates, ${ }^{1}$ it was found:

- for the logistic regression method to work properly, the response scores should estimate the observed response rates quite accurately. This required additional smoothing of the response scores so that they tracked the observed response rates more accurately
- the incremental response tree approach provided better discrimination (lift) than the logistic regression approach, because it attempts to optimise differences in incremental response rates directly.

\section{DECISION RULES FOR CUSTOMER SELECTION}

The incremental response models can be combined with conditional revenue models and gross profit margins to estimate an expected net incremental profit for each customer. All customers with a predicted incremental ROI above the company's hurdle rate, for marketing investments, are then selected for the marketing campaign. This approach based on an expected value decision rule is often termed marketing to expectations, since only customers who are expected 
to contribute positively to the marketing treatment are selected for the campaign.

Note, the above methodology can be extended to not only selecting customers for marketing programmes, but also optimally matching customers to different treatments. Here, instead of a single treatment, the retailer would test a number of competing offers/treatments, in a direct marketing programme. This could be done on the retailer's website with registered customers, or through mail or e-mail campaigns. Instead of calculating a single expected net incremental profit for each customer, an expected net incremental profit is calculated for each treatment, for each customer. Customers are then matched with the treatment with the highest net expected incremental profits. Only those customers who meet the company's hurdle rate requirements for marketing ROI are then selected. Each selected customer is then offered the optimal marketing treatment, based on his or her profile.

\section{SUMMARY}

Retailers today use catalogues, stores and virtual stores to offer and sell

merchandise to consumers. They also use both general media and direct communications to induce customers to buy through their channel of choice. In this environment, the retailer is often drowning in customer level transaction data. This paper discusses how these data can be converted into information and leveraged to make smart direct marketing decisions that get customers to buy more often, place larger orders and keep coming back to the retailer. The following issues are addressed:

- creating an integrated view of the customer
- computing relevant customer performance metrics

— designing marketing programmes based on identified opportunities

— analysis and modelling

— using model-based decision rules to drive marketing investments.

The addition of virtual stores will continue to shift the balance of marketing spend towards direct marketing methods. More customer transaction data will be available than ever before. A company's customer base can now become truly global. This significantly increases customer heterogeneity. The smart retailer will learn to get closer to the customer, better understand the customer's needs and market accordingly. Fortunately, a wealth of analytical tools are available to understand customers better and to predict their behaviours. This paper briefly discussed how some of these tools can be leveraged to maximise customer performance.

Retailers need to view their customers as assets and their key challenge is to grow this asset base through marketing decisions that maximise the cash flow and long-term value of each customer. Technology will continue to develop at a breakneck speed. Today, each customer can have their own virtual store. The challenge for the retailers now is to work out how they should design these stores and how they should entice customers to their individual personalised stores. The answer lies in the analysis of customer transaction data. To be successful in this brave new world, retailers will have to develop significant expertise in this area over the next few years.

\section{Reference}

1 Hansotia, B. J. and Rukstales, B. (2001) 'Incremental value modeling', DMA Research Council Journal, October. 